\title{
Effect of yellow stripe scad (YSS) fish consumption on platelet microparticles markers: Can YYS fish be like salmon in overweight healthy individual?
}

\author{
Yakubu Abdulrahman ${ }^{1,2}$, Azrina Azlan ${ }^{3 \oplus}$, Loh Su Peng ${ }^{3 \oplus}$, Irmi Zarina Ismail ${ }^{4}$, Sabariah Md Noor ${ }^{1}, *(\mathbb{0}$
}

${ }^{1}$ Department of Pathology, Faculty of Medicine and Health Sciences, Universiti Putra Malaysia 43400 Serdang, Selangor

${ }^{2}$ Department of Haematology, Faculty of Medical Laboratory Science, Usmanu Danfodiyo University Sokoto, P.M.P 2346, Sokoto, Northern western Nigeria

${ }^{3}$ Department of Nutrition and Dietetics, Faculty of Medicine and Health Sciences, Universiti Putra Malaysia 43400

Serdang, Selangor

${ }^{4}$ Department of Family Medicine, Faculty of Medicine and Health Sciences, Universiti Putra Malaysia, 43400 Serdang, Selangor

Correspondence

Sabariah Md Noor, Department of Pathology, Faculty of Medicine and Health Sciences, Universiti Putra Malaysia 43400 Serdang, Selangor

Email: md_sabariah@upm.edu.my

History

- Received: Feb 03, 2019

- Accepted: Jul 03, 2019

- Published: Aug 29, 2019

DOI

https://doi.org/10.15419/bmrat.v6i8.561

\section{Check for updates}

\section{Copyright}

(c) Biomedpress. This is an openaccess article distributed under the terms of the Creative Commons Attribution 4.0 International license.

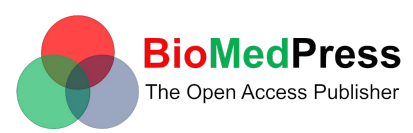

\begin{abstract}
Overweight and obesity is currently a growing burden, according several research data from National Health and Morbidity Survey (NHMS) in Malaysia, shows that in 1999 overweight were at 16,6\%, obesity 4.5\%; in 2006, overweight were at 29.1\%, obesity 14\%, in 2011 overweight were, $29.4 \%$, obesity $15.1 \%$ and in 2015 overweight were $30 \%$, obesity $17.7 \%$. Suggesting that there is parallel prevalence increase, in this sedentary life style in 2015 compared to 1999. Overweight and obesity affects multiple factor such as shifting lifestyles, urbanization, rising income and influence the genetic make-up of life. Currently, it is a great concerned in Malaysia, because it is a risk factor for most inflammatory disease such as cardiovascular disease, cancer and type 2 diabetes, stroke and chronic inflammatory disease, Recent information by Malaysian health minister, won that the country is facing overweight and obesity pandemic problem showing that half of Malaysian population were either overweight or obese. In addition, the latest estimates from the World Health Organization (WHO), show that almost 14\% of the country's citizens fall under the "obese" category in Malaysia. A further 40\% are overweight. Evidence has shown that PMPs interact with sub-endothelial matrix to mobilise monocytes and neutrophils that favour foam cells formation. PMPs play an important role in the transport and delivery of bioactive molecules that can signal inflammation and promote aberrant angiogenesis in diseases such as atherosclerosis, diabetic retinopathy and cancers in overweight. PMPs may affect target cells either by stimulating them via surface-expressed ligands or by transferring surface receptors from one cell to the others. The modulation effect of omega-3 fatty acid (EPA/DHA) from salmon on platelets and endothelial cell markers has been established. American Heart Foundation in collaboration with Committee on Evaluation, Prevention and Detection recommends 250 to $300 \mathrm{mg}$ of cooked salmon per day for the treatment of high blood pressure and cardiovascular diseases. Yellow stripe scad (YSS) is a local Malaysian fish, recently identified to increase HDL-C in overweight subjects. However, the atheroprotective effect of omega-3 fatty acid from YSS on PMPs markers in overweight and obese healthy individuals is still unclear. Thus, the aim of this article is to explore the nutritional value (EPA/DHA) of YSS Fish fillet on platelet microparticles markers that predetermine overweight and obesity risk factors of atherosclerosis.
\end{abstract}

Key words: overweight, leptin, platelet activation, platelet microparticles markers, YSS

\section{INTRODUCTION}

\section{Overweight and obesity in Malaysia}

Overweight/obesity is a growing concern in Malaysia as diseases such as type 2 diabetes, cancer, cardiovascular disease, stroke and chronic diseases are reaching worrying levels, however, a well-balanced diet has vital roles in maintaining normal weight, promoting an overall healthy life and preventing chronic inflammatory disorders such as atherosclerosis, heart diseases, cancers and post-operative morbidity ${ }^{1}$. World Health Organization (WHO) in 2016 has shown that over 1.9 billion adults aged $\geq 18$ years were overweight, whereas more than 650 million aged $\geq 18$ years were obese. Recently, Malaysia was ranked as the country with second highest overweight population in South East Asia ${ }^{2,3}$. Current data from National Health and Morbidity Survey have shown that the prevalence rate of overweight male and female in Malaysia between 2011 and 2015 were at 29.4\% and $30.0 \%$, respectively, and the obesity prevalence rate were at $15.1 \%$ and $17.7 \%$, respectively ${ }^{4-7}$. The presence of activated platelets in overweight subjects generates complex reactions that put healthy subjects at risk of pro-thrombotic state ${ }^{8}$. Atherosclerosis is an inflammatory disease characterized by abnormal lipid metabolism and storage disorder, that cause the infiltration of neutrophil, monocytes and macrophages into the endothelial matrix, via platelet 
activation or PMPs markers on the vascular arterial wall, for foam cell formation ${ }^{8}$. Foam cells are lipid rich core of fat laden, which are formed as a result of monocytes recruitment into the endothelial matrix in the earlier stage of atherosclerotic formation. Several studies have shown that omega-3 fatty acid (EPA+DHA) inhibits expression of platelet activation, PMPs and their related makers, leucocyte recruitment and foam cell formation ${ }^{9-12}$. Salmon fish fillet is wellknown for its cardio-protective properties ${ }^{13-15}$. This review article highlights the complex interactions between overweight with platelets activation, PMPs and its related makers on endothelial cells and vascular smooth muscle cells (VSMC) for the pathogenesis of atherosclerosis. The dietary values of local Malaysian fish, the YSS (EPA/DHA) in comparison to foreign fish, the salmon (EPA/DHA) on PMPs markers to prevent atherosclerosis will also be discussed.

\section{Association between Overweight, Leptin and Platelet Activation}

Overweight is a low grade chronic inflammatory disorder that has been linked to chronic degenerative disease. Several literatures associated this metabolic disorder to excessive adipose tissue that is commonly accompanied by hypertriglyceridemia, hyperinsulinemia, insulin-resistance, decreased HDL cholesterol and hypertension. The occurrence of these multiple factors triggers the atherosclerotic lesions in the endothelium ${ }^{16}$. However, another possible mechanism is involved, i.e. haemostatic imbalance, particularly platelet hyper-reactivity, which aggravates the pathogenesis of atherosclerosis ${ }^{17}$. The latter hypothesis elicits the search for specific circulating factors that may be responsible for the enhanced amplification of acute thrombotic reciprocation to vascular endothelial bed injury in overweight and obese individuals.

Overweight and obesity can be characterised as leptin resistance ${ }^{18}$. Leptin is an adiponectin hormone produced by $O B$ gene and consists of 167 -amino acids, functioning as fat and energy storage regulator in mammals ${ }^{18,19}$. Leptin acts directly in hypothalamic receptors to reduce food appetite and to enhance the energy expenditure level by regulating both fatty acid and glucose metabolism in normal subjects ${ }^{18}$. In fact, studies have shown that high concentration of leptin demonstrates signs of leptin resistance ${ }^{19}$, and the ob/ob mouse that lacks functional leptin, due to nonsense mutation in codon $105 \mathrm{ob}$ - gene, develops severe hyperplasia and excessive obesity ${ }^{20}$. Thus, leptin plays a significant role in this diet-related disorder. Previous literatures also reported that leptin has complex biological roles more/less than the body weight modulation; i.e. leptin was reported to regulate angiogenesis, immune function, fertility, and bone formation, and the presence of leptin receptors can be found in various types of tissues ${ }^{21-23}$. Human platelets were shown to possess the long form of leptin receptors ${ }^{24}$ and high levels of leptin were shown to act collegially along with ADP to foster platelet hypereaction in-vitro ${ }^{25}$. These observations have shown the possibility that leptin resistance may contribute to atherosclerotic lesion that alters the haemostatic balance in overweight subjects (Figure 1 ).

\section{Activated platelets release inflammation markers and platelet microparticles (PMPs)}

Activated platelets release multiple platelet activation markers, which are associated with vascular inflammation and thrombosis that include soluble CD40 ligand (sCD40L), P-selectin, Regulated on Activation, Normal T-cell Expressed and Secreted (RANTES), transforming growth factor- $\beta$ (TGF- $\beta$ ), plateletderived growth factor (PDGF), thromboxane-A2 (TXA2) and platelet factor 4 (PF-4). RANTES mobilises T-cells and monocytes to the injured endothelial cells/VSMC via platelet P-selectin to stimulate monocyte migration and arrest into the vascular endothelium 26,27. PDGF is a platelet growth factor that plays significant roles in proliferation, migration and stimulation of VSMC in the presence of serotonin and TGF- $\beta^{27,28}$. PDGF also acts as monocyte and neutrophil chemotactic factor and signalling via the platelet-derived growth factor receptor (PDGFR) pathway. This pathway plays a significant role in VSMC migration and proliferation, which is a primary characteristic of atherosclerosis ${ }^{29-31}$. PF-4 is a subfamily of CXC chemokine that promotes the differentiation of monocytes into foam cell formation through the interaction of oxidized low-density lipoproteins (LDL) and injured endothelial cells. It also protects the oxidized LDL receptors from degradation $^{32,33}$. sCD40L is a soluble protein released from alpha granules of activated platelets with the structural resemblance to TNF- $\alpha$ superfamily, which is found on the exposed surface of activated platelets. sCD40L increases the stability of new platelet aggregation and facilitates the inflammatory mechanism that involves vascular endothelial cells and reactive oxygen species (ROS). This leads to the expression of adhesion molecules such as Intercellular Adhesion Molecule-1 (ICAM-1), E-selectin and Vascular Cell Adhesion Molecule-1 (VCAM-1) in both VSMC and endothelial cells, including the secretion of matrix metalloproteinase (MMPs), procoagulant factors, 

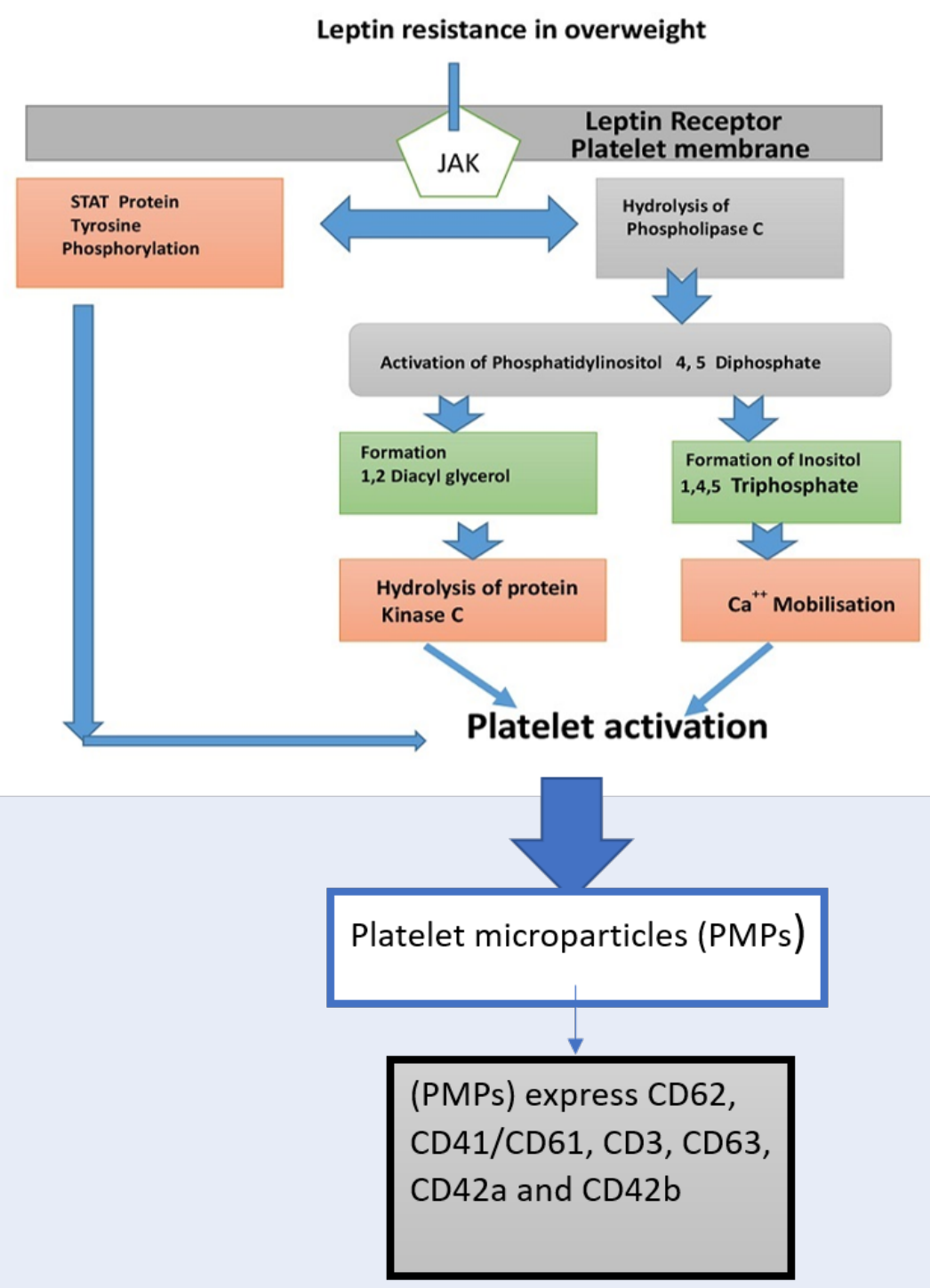

Figure 1: Proposed leptin-dependent pathway of platelet activation in healthy overweight that releases platelet microparticles and markers; P-selectin (CD62P), CD42a(Gplb) and GPIb-V-IX, CD63, platelet endothelium adhesion molecule-1 (PECAM-1(CD31), integrin glycoprotein (GP) Ilb/llla, (CD41 and CD61). 
cytokines and chemokines ${ }^{34,35}$. Activated platelets also release PMPs for their normal physiological function. The small size and structure of PMPs make them an important cargo in platelet cell communication and a delivery agent of platelet - borne bio-active molecules such as platelet activation markers, platelet inflammation cytokines, signalling molecules, growth factors, and microRNAs (miRNA) ${ }^{36}$. An increased level of plasma PMPs was shown to occur in subjects with few pathological conditions such as overweight with type 2 diabetes or non-overweight with type 2 diabetes ${ }^{37}$. In contrast, overweight subjects in the absence of diabetic condition shows no effect of PMPs markers, but an increased level of PMPs without markers was observed ${ }^{37}$. Increased levels of specific positive PMPs markers in subjects with a diabetic condition may provide a potential pathway by which PMPs contribute to the pathogenesis of atherosclerosis and cardiovascular events Figure 2.

Janowska-Wieczorek and colleagues have shown that haematopoietic stem-progenitor cells expressed PMPs membrane receptors such as CD62, CD41, PAR-1 and CXCR4 that encourage the engraftment of progenitor cells to the endothelium ${ }^{38}$. This observation suggests that PMPs from activated platelets play a significant role in stem cell transplantation and recipient cells, which affects the cell function of the recipients. PMPs engulf cytoplasmic membrane during their formation to acquire protein and RNA from the cytosol of the parent cells. Multiple evidence have suggested that following the attachment or fusion of PMPs to the target cells, PMPs will transfer the RNA and protein content to the recipient cells ${ }^{39-41}$. This process facilitates the recipient cell to internalise PMPs via endocytosis or through receptor-ligand interactions ${ }^{42}$, which suggests that PMPs could reprogram a target cells. Ratajczak et al., shown that microparticles derived from embryonic stem cells reprogramed the haematopoietic stem cell progenitors via the horizontal transfer of protein and mRNA delivery ${ }^{43}$. Other studies have shown that microparticles from endothelial cell induced angiogenesis in both in-vivo and in-vitro via horizontal transfer of mRNA to human macrovascular and microvascular endothelium ${ }^{44}$. The $\mathrm{CD} 41^{+}$microparticles are known to have coagulant properties, however, the anticoagulant properties are still unknown.

\section{Pathophysiology of PMPs and its related markers in atherosclerosis}

PMPs are known to play an important haemostatic role, by which the inability of platelets to generate
PMPs was linked to bleeding episode (Castaman's defect $)^{45}$. Secondly, platelets in patient with Scott's syndrome shows impaired ability to generate PMPs and displays a bleeding diathesis. PMPs were demonstrated to play significant roles in the activation of vascular endothelial cells, exposure of PMPs to endothelial phospholipase A2, and stimulation of arachidonic acid release from both platelets and endothelial cells, which are subsequently metabolised to produce thromboxane A2 ${ }^{46}$. The trans-activation of both platelets and endothelial cells further promotes the interactions of monocyte endothelial cells ${ }^{47}$. Berckmans and colleagues reported that the presence of PMPs in healthy individuals, particularly the CD $41^{+}$ micropartiples, are known to generate thrombin ${ }^{48}$. $\mathrm{CD} 41^{+}$microparticles are highly procoagulant in nature. The presence of $\mathrm{CD} 41^{+}$receptors on PMPs may contribute to the pathogenesis of arterial thrombosis disease. Several literatures have demonstrated that circulating PMPs may provide a potential diagnostic and prognostic makers of atherosclerotic vascular disease ${ }^{2,49-51}$. CD63-exposing and P-selectin from PMPs reflect the platelet activation markers in myocardial infarction and peripheral arterial disease ${ }^{52}$. Michelsen et al., have shown that increased levels of PMPs was observed in myocardial infarction survivors $^{53}$. PMPs have been shown to be independent of large PMPs, soluble CD40 ligand (sCD40L) and plasma thrombin-antithrombin complexes in patients with myocardial infarction, but not in healthy controls. Another study by Chironi et al. demonstrated that the diameter of both internal and external carotid artery were negatively correlated with PMPs derived from platelets, endothelial cells and leucocytes ${ }^{54}$. It is, however, still unclear about the effect of omega-3 fatty acid (EPA/DHA) from YSS fish fillet on PMPs (CD41) and its related markers such as P-selectin (CD62P), CD42a (GpIb), GPIb-V-IX, CD63, platelet endothelium adhesion molecule-1 (PECAM-1(CD31), integrin glycoprotein (GP) IIb/IIIa.

\section{Platelet microparticles (PMPs) in endothe- lial cells and atherosclerosis}

Endothelial cells (ECs) are the barrier that maintains the balance between the circulatory molecules and the cells. It is the key modulator of vascular homeostasis, which plays an essential role in signal transduction that affects the reorganization of vascular wall physical composition ${ }^{55}$. ECs release certain vascular - balanced chemical molecules such as nitric oxide (NO), endothelia, prostaglandin I2 and endotheliumderived relaxing factor that maintains the integrity of 


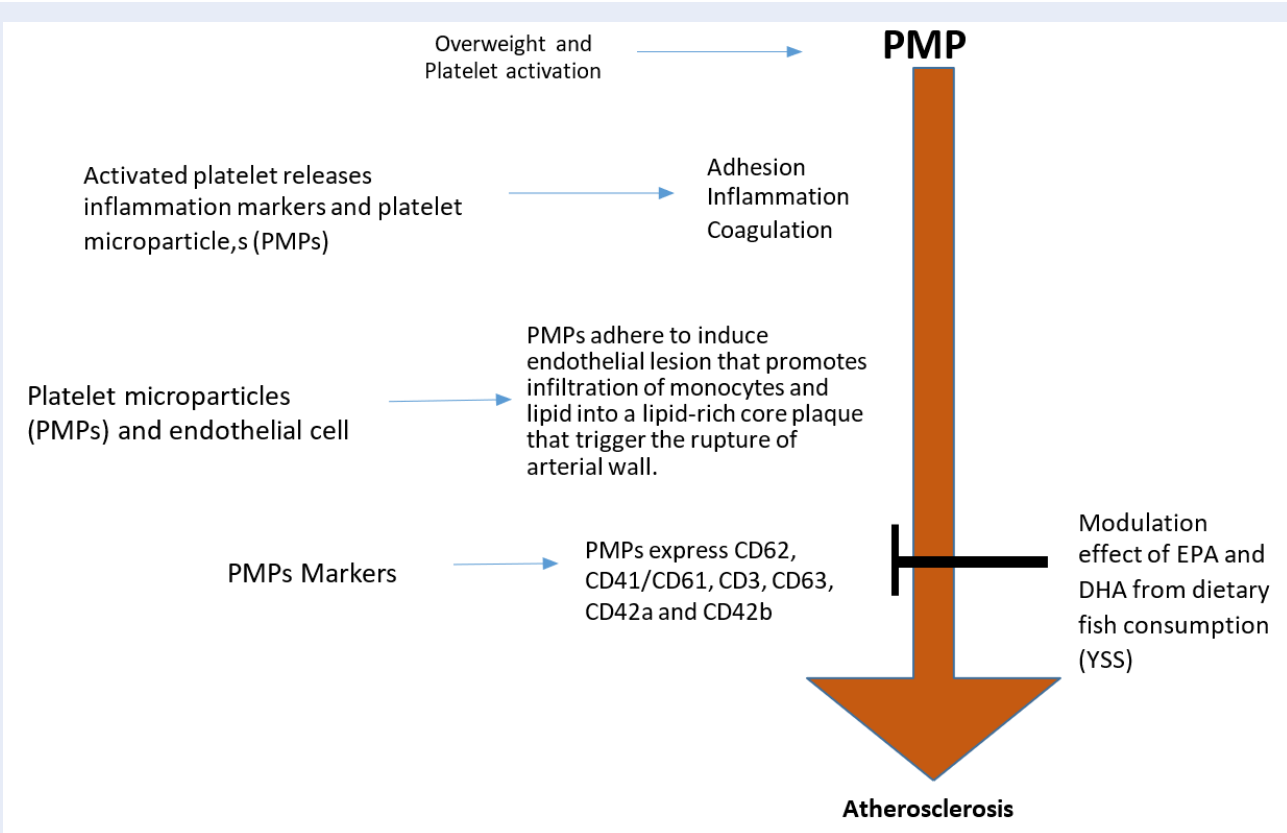

Figure 2: Atherosclerosis is an inflammatory disease linked to platelet microparticles (PMPs) that is characterised with inflammation, adhesion, and lipid deposition and procoagulation. Endothelial damage influences the adhesion of PMPs to vascular endothelial cell and induces the proliferation, apoptosis and transmigration endothelial cell. The endothelial cell mobilizes proteins such as ICAM-1,GPIIb/GPIIla, and RANTES. The presence of PMPs increases the adhesion of molecules to mobilize monocytes and leucocytes into subendothelial layer to enhance vascular inflammation in the endothelial lesion. For example, iCAM-1, MPO, 1L-8 and 1L-10 are known to be involved in this process. Besides that, ox-LDL can easily activates platelet through CD36, called scavenger receptor, to release PMPs and dysfunctional HDL to form the bases of atherosclerosis that can be inhibited by DHA and EPA via PMPs markers.

vascular beds. It also releases anticoagulation proteins such as tissue factors and plasminogen activators, which are important in fibrinolytic system. Thus, healthy and normal ECs inhibit the adhesion and aggregation of platelets to vascular endothelial wall, which facilitates a range vascular tone regulatory factors including smooth muscle cell proliferation, vascular wall inflammation, cellular adhesion and thromboresistance ${ }^{56}$. The release PMPs from activated platelets systematically affects the activities of other cell types as summarized in Figure $3^{57}$. PMPs are protein and lipid complexes with an average size of $\leq 1 \mu \mathrm{m}$. It is a minor fragment of platelet $\alpha$-granules and phospholipid membrane ${ }^{58}$. Apart from other microparticles present in circulation, PMPs are made up of 70\%-90\% of circulatory blood and their cargo content are relevant in both inflammation and haemostasis, as it also enhance coagulation, mediate leucocytes adhesion to subendothelial matrix and promote stimulation of VSMC angiogenesis ${ }^{59,60}$. Thus, the effect of PMPs markers on endothelial cells and VSMC can be characterized as chronic inflammation ${ }^{61}$ and one of the observed effects of PMPs markers on endothelial cells is the synthesis of interleukin 1 beta (IL- $1 \beta$ ). IL- $1 \beta$ is an active cytokine that stimulates the production of adhesion and chemoattractant molecules such as MCP-1, VCAM-1 and ICAM-1 via NF-k B ${ }^{61}$. Thus, PMPs can be characterised as active mediators between the leucocytes and inflammatory cytokines ${ }^{62}$. PMPs markers recruit monocytes and RANTES to the site of injured endothelial cells ${ }^{63}$. The quantification of PMPs and its related markers can be conducted using two methods, the flow cytometer measurement (FCM) and enzyme-linked immunosorbent assays (ELISA) ${ }^{3,64}$. PMPs can be distinguished from other exosomes obtained from multivesicular endosomes as smaller MPs are found in $\alpha$ granule-derived proteins while larger MPs are derived from platelet phospholipid membrane that express mitochondrial proteins. Thus, the evaluation of PMPs markers such as P-selectin (CD62P), CD42a (GpIb) and GPIb-V-IX, CD63, platelet endothelium adhesion molecule-1 (PECAM-1(CD31), integrin glycoprotein (GP) IIb/IIIa, CD41 and CD61 ${ }^{65,66}$ in over- 
weight subjects can be obtained using flow cytometry and the therapeutic effect of omega-3 fatty acid (EPA/DHA) from YSS fish fillet on these markers will be monumental to treat these diet-related disorders (Figure 3) .

\section{Selected platelet microparticles marker in atherosclerosis}

P-selectin (CD62P): is an adhesion molecule that links PMPs to endothelial cells (ECs). Increased levels of PMPs and P-selectin in blood circulation is a sign of diabetes, hyperlipidemia, hypertension and overweight. P-selectin in diabetes patients are known to be associated with thrombotic events, such as retinopathy, coronary heart disease and atherosclerosis. The PMPs level is associated with platelet activation by expression of platelet P-selectin ${ }^{67}$. It is indeed, to note that, PMPs target in cardiovascular treatment are still limited ${ }^{68}$. PMPs with omega-3 fatty from YSS may modulate P-selectin levels as compared to those from salmon in both platelet and ECs.

\begin{tabular}{lllll} 
CD42a $\quad(G p I b)$ & and & \multicolumn{2}{c}{ GPIb-V-IX, or } \\
GPIb $\alpha / \mathbf{I b} \beta / \mathrm{V} / \mathbf{I X}$ & $:$ are also known as \\
$\mathrm{CD} 42 \mathrm{~b} \alpha / \mathrm{CD} 42 \mathrm{~b} \beta /$ & $\mathrm{CD} 42 \mathrm{~d} / \mathrm{CD} 42 \mathrm{a}$ & respectively,
\end{tabular} are four of the glycoproteins belong to leucine-rich family. It facilitates platelets adhesion to vWF during vascular endothelial damage ${ }^{69}$. Deficiency of one of these four proteins can lead to Bernard-Soulier syndrome, which is a severe blood bleeding disorder. The interaction between vWF and GPIb-V-IX ${ }^{70}$ signals the transduction to activate platelet integrin (GPIIb/IIIa). This mechanism was observed in Apoe $^{-/-}$mice injected with GPIb $\alpha$, by which a drastic reduction in atherosclerosis lesion size was observed ${ }^{71}$. The observation indicates that GPIb $\alpha$ binding to vWF on endothelial cell is highly pro-inflammatory.

PMPs and platelet integrin aIIb $\beta 3$ (GpIIb-IIIa): Platelet integrin belongs to the fibrinogen receptor family that is crucial for platelet activation, which can be found on the platelet membrane and the CD41/CD61 complex. Platelet integrin is also known as glycoprotein (GP) IIb/IIIa. The combination of CD41 and CD61 is associated with non-covalent bonding with fibrinogen, which is the basis of platelet aggregation ${ }^{72}$. Thus, the presence of this receptor (IIb/IIIa) in PMPs during acute coronary disorder allows the binding of PMPs to vascular wall, which will initiate a signal transduction pathway such as extracellular signal-regulated kinase, phosphoinositide 3-kinase (PI3-kinase) pathways, and activation of pertussis-toxin-sensitive $\mathrm{G}$ protein ${ }^{73}$. Studies have shown the association between high levels of PMPs with various diseases such as sickle cell disease, malignant tumour formation, thrombocytopenic purpura, cardiovascular diseases and haemolytic disorders ${ }^{65,74}$

\section{Modulation effects of fish fillet (EPA and DHA) on platelet microparticles (PMPs) markers}

A meta-analysis of randomised clinical intervention trials have shown that omega-3 fatty acid (EPA/DHA) reduced the procoagulant function of platelets and cardiovascular disease $(\mathrm{CVD})^{75}$. Other studies have shown a significant beneficial effects of EPA/DHA on platelet functions in type $2 \mathrm{DM}$ and coagulation profile in patients with vascular complications, with marginal favourable effects on the glycaemic status and lipid profiles ${ }^{76}$. A pilot study of omega- 3 fatty acid supplementation have shown the occurrence of attenuated platelet activation even among patients that took aspirin or aspirin plus clopidogrel $^{77}$. Omega-3 fatty acid (EPA/DHA) exerts a gender-based dependent effects on platelet microparticles and platelet activation but not on MP levels. With regards to thrombotic disease risk, males may benefit more from EPA supplementation ${ }^{78}$. Other effects of EPA/DHA include protection against CVD by reducing serum triacylglycerides $(\mathrm{TAG})^{79}$, heart rate $^{80}$, blood pressure (BP $)^{81}$, and serum homocysteine levels ${ }^{82}$, as well as regulating and resolving inflammatory process ${ }^{83}$ as shown in randomized trials with fish oil supplementation. However, other reports have shown that omega-3 have no effect on platelet aggregation ${ }^{84}$. Despite so, there is a paucity of available data on yellow stripe scad (YSS) as a source of omega3 fatty acid in overweight healthy subjects.

\section{Current available data}

In human, immune cells such as monocytes, lymphocytes, neutrophils and platelets are regarded as inflammatory cells that protect the body against foreign invaders. High levels of omega-3 fatty acid (EPA/DHA) in the phospholipid membrane allows the cells to function effectively. However, in overweight individuals, the level of EPA/DHA is compromised with the higher level of omega- 6 fatty acid (Arachonic acid) at $10-20 \%$ that decreases docosahexaenoic acid (DHA) to $2-4 \%$ and eicosapentaenoic acid (EPA) to $0.5-1 \%{ }^{85,86}$. Even so, the level of omega-3 fatty acid in phospholipid membrane can be altered as omega-3 fatty acid can be obtained from fish and plant sources, despite the fact that the 

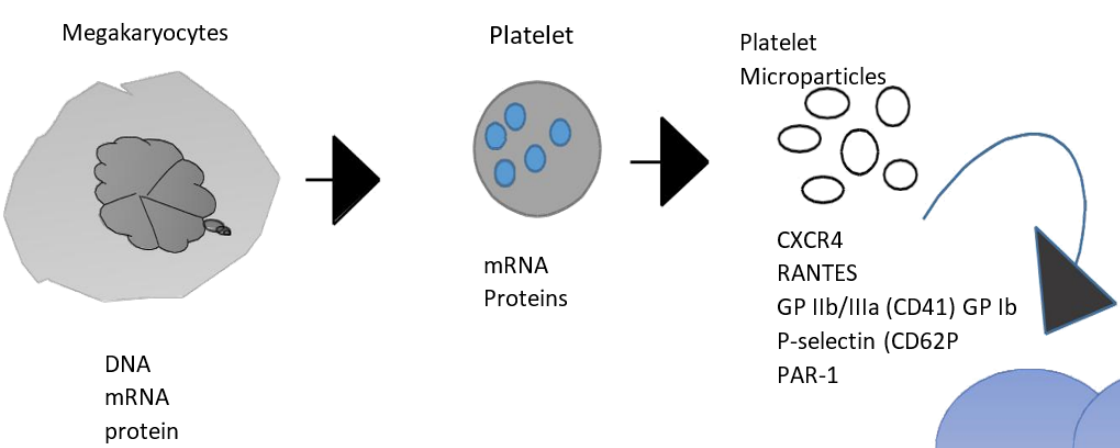

mRNA

PAR-1

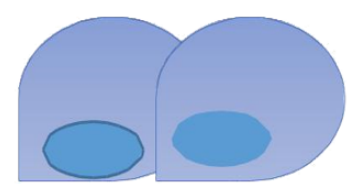

Figure 3: PMPs are microvesicles with approximately $0.1-1 \mu \mathrm{m}$ in size and they are released from activated platelets with the aid physiological agonist such as collagen or thrombin. PMPs express some function markers such P-selectin (62P), adhesion receptor, GP IIb/IIla (CD41), PAR-1, GPIb and CXCR4. PMPs also contain different coagulation proteins and have a role in the haemostatic response to inflammation. PMPs activate the endothelial and stimulate cytokine and adhesion molecules to release their content, promoting the contraction of VSMC. PMPs were found in high concentration in patients with acute vascular syndromes, obesity, diabetes mellitus and atherosclerosis.

body does not produce omega-3 fatty acid. Currently, three types of fish samples were identified to contain a desirable amount of omega-3 fatty acids (EPA/DHA). Yellow stripe scad (YSS) showed the highest DHA with a Polyunsaturated/Saturated (P/S) $=1.7$, moonfish showed the highest ALA with a P/S $=1.0$, and longtail shad showed the highest EPA with $\mathrm{P} / \mathrm{S}=0.4)^{87}$. The intake of omega-3 fatty acid from fish fillets, especially from salmon, was shown to change the ratio of omega- 6 to omega- 3 fatty acid in favour of omega-3 phospholipid membrane that modulates the cellular inflammation via blood cells in overweight and obese subjects. Previous study by A bdulazeez et al., 2013 has shown that omega3 fatty acid content in most Malaysian fishes contain lower EPA that falls between $2.7-343.0 \mathrm{mg} / 100$ g wet sample ${ }^{87}$ in comparison to salmon feed (2638 $\mathrm{mg} / 100 \mathrm{~g})$, farmed salmon (1079 $\mathrm{mg} / 100 \mathrm{~g})$, supermarket salmon (969 mg/100 g), and wild salmon (414 $\mathrm{mg} / 100 \mathrm{~g})^{88}$. However, longtail shad with 1327.4 $\mathrm{mg} / 100 \mathrm{~g}$ wet sample EPA ${ }^{88}$ was found to be comparable to salmon feed ( $2638 \mathrm{mg} / 100 \mathrm{~g}$ wet sample), ${ }^{88}$ suggesting that EPA from longtail shad can be associated with protective effects from the occurrence of asthma, coronary heart problems and many other diseases ${ }^{89,90}$. Meanwhile, DHA values (629-2633 $\mathrm{mg} / 100 \mathrm{~g}$ ) from previous studies on salmon fish fillets have shown that it is not comparable to the values (9.0-277.1 mg/100 g wet sample) by Abdul-Aziz et al., 2013. However, YSS with $782.1 \mathrm{mg} / 100 \mathrm{~g}$ wet sample was found to contain slightly higher DHA content as compared to wild salmon $(629 \mathrm{mg} / 100 \mathrm{~g})^{88}$. A study by Chang WL et al ., 2017 showed that YSS could increase HDL-C levels in overweight subjects ${ }^{91}$, further suggesting that YSS fish fillets are comparable to wild salmon, and the omega- 3 fatty acid in salmon fish fillets was shown to be cardioprotective. American Heart Foundation recommends the intake of omega3 fatty acid at $250-300 \mathrm{mg} /$ day for heart disease patients and it is indeed, to note that majority of fish oil capsule production contains salmon. Despite so, the effect omega-3 fatty acid (EPA/DHA) from YSS on PMPs and thrombosis is still unclear. Therefore, it is promising that the consumption of YSS at 250$300 \mathrm{mg} /$ day with reference to recommendation by American Heart Foundation ${ }^{92}$ may ameliorates overweight/obesity -related risk factors such as platelet activation, PMPs and cardiovascular diseases.

\section{CONCLUSION}

This review article emphasised the role of EPA/DHA in overweight and obesity subjects on PMPs- related biomarkers. The EPA/DHA content in fishes differs from one fish to another in terms of quantity and quality. Despite so, several studies have shown the comparisons between EPA/DHA content of salmon and other fatty fishes. DHA is quantitatively the most important omega-3 PUFA in salmon and has consistently been shown to have unique and indispensable 
roles in platelet phospholipid membrane and cardiovascular diseases. Overweight and obesity subjects were shown to have deficits in EPA/DHA levels due to the higher levels of omega- 6 fatty acid (arachidonic acid) on the platelet cellular membrane. Therefore, it is therapeutically promising. Intervention studies in 2017 have shown that EPA and DHA from YSS increase $d$ the levels of HDL-C in overweight subjects, suggesting that the consumption of YSS at 250-300 $\mathrm{mg} /$ day could reduce the levels of platelet activation, PMPs marker, atherosclerosis and other related risk factors in overweight healthy people.

\section{ABBREVIATIONS}

ADP: Adenosine diphosphate

BP: Blood Pressure

CD41/CD61: integrin glycol protein (GP) IIb/IIIa

$\mathrm{CD41}^{+}$: Platelet microparticle marker

CD42a: GpIb, GPIb-V-IX,

CD62: P-selectin

CD62E: E-selectin

CVD: Cardiovascular Disease

CXC: chemokine

CXCR4: CD184 chemokine

DHA: Docosahexaenoic Acid

ECs: Endothelial cells

ELISA: Enzyme-Linked Immunosorbent Assays

EPA: Eicosapentaenoic Acid

HDL-C: High-Density Lipoprotein Cholesterol

ICAM-1: Intercellular Adhesion Molecule-1

IL-1 $\beta$ : Interleukin- $1 B$

LDL-C: Low-density lipoprotein $(L D L)$ cholesterol

MCP-1: Monocyte Chemoattractant Protein-1

miRNA: microRNAs

MMPs: Matrix metallopeptidases

NO: Nitric Oxide

OB-gene: Obesity gene

PAR-1: Protease-Activated Receptors-1

PDGF: Platelet-Derived Growth Factor

PDGFR: Platelet-Derived Growth Factor Receptor

PECAM: Platelet Endothelium Adhesion Molecule-1 (CD31),

PF-4: Platelet factor 4

PI3: Phosphatidylinositol3-kinase

PMPs: Platelet Micro-Particles

RANTES: Regulated on Activation Normal T-cell Expressed and Secreted

ROS: Reactive Oxygen Species

sCD40L: Soluble CD40 ligand

TAG: Triacylglycerides

TGF- $\beta$ : Transforming growth factor- $\beta$

TNF- $\alpha$ : Tumor Necrosis Factor alpha

TXA2: Thromboxane-A2
VCAM-1: Vascular Cell Adhesion Molecule-1

VSMC: Vascular Smooth Muscle Cells

vWF: Von Willebrown Factor

WHO: Word Health Organization

YSS: Yellow Stripe Scad

\section{COMPETING INTERESTS}

The authors declare no conflicts of interest regarding the publication of this paper.

\section{AUTHORS' CONTRIBUTIONS}

Conception and design of study: Yakubu Abdulrahman, Azrina Azlan' Loh Su Peng, Irmi Zarina Ismail Sabariah Md Noor (all authors)

Acquisition of data: Yakubu Abdulrahman Analysis and/or interpretation of data: All authors Drafting the manuscript: Yakubu Abdulrahman, Sabariah Md Noor

Revising the manuscript critically for important intellectual content: Azrina Azlan' Loh Su Peng, Irmi Zarina Ismail, Sabariah Md Noor

Approval of the version of the manuscript to be published (the names of all authors must be listed): Yakubu Abdulrahman, Azrina Azlan' Loh Su Peng, Irmi Zarina Ismail, Sabariah Md Noor

\section{ACKNOWLEDGMENTS}

This work was supported by the Geran Putra IPS (Putra Grant Initiative) from Universiti Putra Malaysia (UPM).

\section{REFERENCES}

1. Kylasov A, Gavrov S. Diversity of Sport: non-destructive evaluation. In: UNESCO: Encyclopedia of Life Support Systems; 2011. p. 462-91.

2. Ng M, Fleming $T$, Robinson $M$, Thomson B, Graetz N, Margono $C$, et al. Global, regional, and national prevalence of overweight and obesity in children and adults during 1980-2013: a systematic analysis for the Global Burden of Disease Study 2013. The Lancet. 2014;384(9945):766-81. Available from: 10.1016/S0140-6736(14)60460-8.

3. Schmid I, editor. Flow Cytometry; 2012. Available from: 10.5772/2045;https://www.intechopen.com/books/flowcytometry-recent-perspectives.

4. National Health And Morbidity Survey ( Nhms ) 2017 : Key Findings from the Adolescent Health and Nutrition Surveys. 2018;(April):1-29.

5. Tsioufis KP, Dimitriadis K, Koutra E, et al. The metabolic syndrome: Requiescat in Pace. Clin Chem. 2005;51(6):931-938.

6. Institute for Public Health. National Health and Morbidity Survey 2015 (NHMS 2015). Vol. II: Non-Communicable Diseases, Risk Factors \& Other Health Problems. Vol II. 2015;Available from: 10.1017/CBO9781107415324.004.

7. Ying $Y C$, Kuang $K L$, Kuang $H L$, Chien $H T$, Chee $C K$, Siew $M C$, et al. Physical activity and overweight/obesity among Malaysian adults: findings from the 2015 National Health and morbidity survey (NHMS). BMC Public Health. 2017;17:733733. Available from: $10.1186 / \mathrm{s} 12889-017-4772-z$.

8. Mertens I, LF LFVG. Obesity, haemostasis and the fibrinolytic system. Obes Rev. 2002;3(2):85-101. 
9. Domschke G, Gleissner CA. CXCL4-induced macrophages in human atherosclerosis. Cytokine. 2017;(17):30254-30259. Available from: 10.1016/j.cyto.2017.08.021.

10. Amanda LB, Xuewei Z, Shunxing R, Swapnil S, Jeongmin S, EB. Omega-3 Fatty Acids Ameliorate Atherosclerosis by Favorably Altering Monocyte Subsets and LimitingMonocyte Recruitment to Aortic Lesions. Arteriosclerosis, Thrombosis, and Vascular Biology. 2012;32:2122-2130. Available from: .org/10. 1161/ATVBAHA.112.253435.

11. McEwen BJ. The influence of diet and nutrients on platelet function. Semin Thromb Hemost. 2014;40(2):214-240. Available from: 10.1055/s-0034-1365839.

12. Turco D, Basta S, Lazzerini G, Evangelista G, Rainaldi M, Tanganelli $G$, et al. Effect of the administration of $n-3$ polyunsaturated fatty acids on circulating levels of microparticles in patients with a previous myocardial infarction. Haematologica. 2008:93(6):892-901. Available from: 10.3324/haematol.11845.

13. Seierstad SL, Seljeflot I, Johansen O, Hansen R, Haugen M, Rosenlund G. Dietary intake of differently fed salmon; the influence on markers of human atherosclerosisEur. J Clin Invest. 2005;35(1):52-61. Available from: DOI:10.1111/j.1365-2362. 2005.01443.x.

14. Parolini C, Vik R, Busnelli M. A salmon protein hydrolysate exerts lipid-independent anti-atherosclerotic activity in apoEdeficient mice. PLoS One. 2014;9(5):1-9. Available from: 10.1371/journal.pone.0097598.

15. Vikren LA, Drotningsvik A, Bergseth MT, Mjs SA, Mola N, Leh S. Effects of baked and raw salmon fillet on lipids and n-3 PUFAs in serum and tissues in Zucker fa/fa rats. Food Nutr Res. 2017;12(1):1333395-1333395. Available from: 10.1080/ 16546628.2017.1333395.

16. Kaur J. A comprehensive review on metabolic syndrome. Cardiol Res Pract. 2014;p. 943162-943162. Available from: $10.1155 / 2014 / 943162$.

17. Jax TW, Peters AJ, Plehn G, Schoebel C. Hemostatic risk factors in patients with coronary artery disease and type 2 diabetes - a two year follow-up of 243 patients. Cardiovasc Diabetol. 2009;7:48-48. Available from: 10.1186/1475-2840-8-48.

18. Martin GM, Rudolph L, S RJ, . Obesity and Leptin Resistance: Distinguishing Cause from Effect. Trends Endocrinol Metab. 2010;21(11):643-651. Available from: 10.1016/j.tem.2010.08. 002.

19. Harris RBS. Direct and indirect effects of leptin on adipocyte metabolism. Biochim Biophys Acta. 2014;1842(3):414-437. Available from: 10.1016/j.bbadis.2013.05.009.

20. Lindstrom P. The physiology of obese-hyperglycemic mice. Scientific World Journal. 200729;7:666-685. Available from: DOI:10.1100/tsw.2007.117.

21. Fantuzzi G, Faggioni R. Leptin in the regulation of immunity inflammation, and hematopoiesis; 2000. Available from: 10 . 1189/jlb.68.4.437.

22. Elbatarny HS, Maurice DH. Leptin-mediated activation of human platelets: involvement of a leptin receptor and phosphodiesterase $3 \mathrm{~A}$-containing cellular signaling complex. Am J Physiol Endocrinol Metab. 2005;289(4):695-702. Available from: DOI:10.1152/ajpendo.00125.2005.

23. Priego T, Snchez J, Palou, Pic C. Effect of high-fat diet feeding on leptin receptor expression in white adipose tissue in rats: depot- and sex-related differential response. Genes Nutr. 2009:4:151-156. Available from: 10.1007/s12263-009-0114-9.

24. Giandomenico G, Dellas C, Czekay RP, Koschnick S, Loskutoff DJ. The leptin receptor system of human platelets. J Thromb Haemost. 2005;3(5):1042-1051. Available from: DOI:10.1111/ j.1538-7836.2005.01327.x.

25. Lukasik M, Michalak S, Dworacki G, Siewiera K, Kaczmarek M, Watala C. Reactive leptin resistance and the profile of platelet activation in acute ischaemic stroke patients. Thromb Haemost. 2012;108(1):107-125. Available from: 10.1160/ TH11-12-0860.DOI:10.1160/TH11-12-0860.

26. Vilahur $\mathrm{L}$, Vilahur $\mathrm{G}$. Thrombosis formation on atherosclerotic lesions and plaque rupture. J Intern Med. 2014;276(6):618650. Available from: 10.1111 /joim.12296.
27. Sonmez O, Sonmez M. Role of platelets in immune system and inflammation. Porto Biomedical Journal. 2017;2(6).

28. Blair P, Flaumenhaft R. Platelet a -granules : Basic biology and clinical correlates. Blood Rev. 2009;23(4):177-189. Available from: 10.1016/j.blre.2009.04.001.

29. Deuel TF, Senior RM, Huang JS, Griffin GL. Chemotaxis of Monocytes and Neutrophils to Platelet-derived Growth Factor. J Clin Invest. 1982;69(4):1046-1055. Available from: 10.1172/JCI110509.

30. Martin R, Bennett S, Sinha GK, Owens. Vascular smooth muscle cells in atherosclerosis. Circ Res. 2016;118:692-702. Available from: 10.1161/CIRCRESAHA.115.306361.

31. Montecucco F, Mach F. Atherosclerosis is an inflammatory disease. Semin Immunopathol. 2009;31(1). Available from: 1-3.doi:10.1007/s00281-009-0146-7.

32. Lindemann S, Kra B, Seizer P, M G. -Platelets, inflammation and atherosclerosis. J Thromb Haemost. 2007;5. Available from 10.1111/j.1538-7836.2007.02517.x.

33. Aloui C, Prigent A, Sut $C$, Tariket $S$, Hamzeh-Cognasse $H_{t}$ Pozzetto $\mathrm{B}$. The signaling role of CD40 ligand in platelet biology and in platelet component transfusion. Int J Mol Sci. 2014;3(12):22342-64. Available from: 10.3390/ijms151222342.

34. Kooten CV, Banchereau J. CD40-CD40 ligand. J Leukoc Biol. 2000;67(1):2-17. Available from: 10.1002/jlb.67.1.2.

35. Prasad K, Andre P, He M, Bao M, Manganello J, Phillips DR. Soluble CD40 ligand induces 3 integrin tyrosine phosphorylation and triggers platelet activation by outside-in signaling. Proc Natl Acad Sci. 2003;100(21):12367-12374.

36. Lazar S, Goldfinger LE. Platelet Microparticles and miRNA Transfer in Cancer Progression: Many Targets, Modes of Action, and Effects Across Cancer Stages. Front Cardiovasc Med. 2018;28(5):13. Available from: 10.3389/fcvm.2018.00013.

37. Stepanian A, Bourguignat L, Hennou S, Coupaye M, Hajage D, Salomon $\mathrm{L}$, et al. Microparticle Increase in Severe Obesity: Not Related to Metabolic Syndrome and Unchanged after Massive Weight Loss. 2013;21(11):2236-2243. Available from: 10.1002/ oby. 20365.

38. Janowska-Wieczorek A, Majka M, Kijowski J, Reca R, Turner AR. Platelet-derived microparticles bind to hematopoietic stem/progenitor cells and enhance their engraftment. Blood. 2001;98(10):3143-3149. Available from: 10.1182/blood.V98. 10.3143.

39. Ratajczak J, Wysoczynski M, Hayek F, Janowska-Wieczorek A Ratajczak MZ. Membrane-derived microvesicles: Important and underappreciated mediators of cell-to-cell communication. Leukemia. 2006;20(9):1487-1495. Available from: 10. 1038/sj.leu.2404296.

40. Laffont B, Provost P. Activated platelets can deliver mRNA regulatory Ago2 microRNA complexes to endothelial cells via microparticles. Blood. 2013;122(2):253-61. Available from: 10.1182/blood-2013-03-492801.

41. Xia L, Zeng Z, Tang WH. The Role of Platelet Microparticle Associated microRNAs in Cellular Crosstalk. Front Cardiovasc Med. 2018;5:29-29. Available from: 10.3389/fcvm.2018.00029.

42. Clayton A, Turkes A, Dewitt S, Steadman R, Mason MD, Hallett $M B$. Adhesion and signaling by $B$ cell-derived exosomes: the role of integrins. FASEB J. 2004;18(9):977-986. Available from: DOI:10.1096/fj.03-1094fje.

43. Ratajczak J, Miekus K, Kucia M, Zhang J, Reca R, Dvorak P. Embryonic stem cell-derived microvesicles reprogram hematopoietic progenitors: Evidence for horizontal transfer of mRNA and protein delivery. Leukemia. 2006;20(5):847-856. Available from: 10.1038/sj.leu.2404132.

44. Deregibus MC, Cantaluppi V, Calogero R, Tetta C, Biancone L. Endothelial progenitor cell - Derived microvesicles activate an angiogenic program in endothelial cells by a horizontal trans fer of mRNA. Blood. 2007;110(7):2440-2448. Available from: 10.1182/blood-2007-03-078709.

45. Castaman G, Yu-Feng L, Rodeghiero F. A bleeding disorder characterised by isolated deficiency of platelet microvesicle generation. Lancet. 1996;347(9002):700-701. Available from: 
10.1016/S0140-6736(96)91259-3.

46. Barry OP, Pratic D, Lawson JA, Fitzgerald GA. Transcellular activation of platelets and endothelial cells by bioactive lipids in platelet microparticles. J Clin Invest. 1997;99(9):2118-2127. Available from: 10.1172/JC11 19385.

47. Barry OP, Pratic D, Savani RC, Fitzgerald GA. Modulation of monocyte-endothelial cell interactions by platelet microparticles. J Clin Invest. 1998;102(1):136-144. Available from: 10.1172/JCI2592.

48. Hack CE, Bing AN, Sturk A, Romijn FP, Berckmans RJ, Nieuwland R. Cell-derived microparticles circulate in healthy humans and support low grade thrombin generation. Thromb Haemost. 2001;85(4):639-646. pii.

49. Boulanger CM, Amabile N, Tedgui A. Circulating microparticles: A potential prognostic marker for atherosclerotic vascular disease. Hypertension. 2006;48(2):180-186. Available from: 10.1161/01.HYP.0000231507.00962.b5.

50. Wang M, Fu Y, Xu L, Yue Y, Liu S. Diagnostic value of platelet \&\#8209; derived microparticles in pulmonary thromboembolism : A population \&\#8209; based study. Exp Ther Med. 2018;16(4):3099-3106. Available from: 10.3892/etm.2018. 6579.

51. Yun S, Sim E, Goh R, Park J, Han J. Platelet Activation : The Mechanisms and Potential Biomarkers. Biomed Res Int. 2016;p. 9060143-9060143. Available from: 10.1155/2016/ 9060143.

52. Zee PMVD, Bir E, Ko Y, Winter RJD, Hack CE, Sturk A, et al. P-selectin- and CD63-exposing platelet microparticles reflect platelet activation in peripheral arterial disease and myocardial infarction. Clin Chem. 2006;52(4):657-664. Available from: 10.1373/clinchem.2005.057414.

53. Michelsen AE, Brodin E, Brosstad F, Hansen JB. Increased level of platelet microparticles in survivors of myocardial infarction. Scand J Clin Lab Invest. 2008;68(5):386-392. Available from: 10.1080/00365510701794957.

54. Chironi GN, Simon A, Boulanger CM, Dignat-George F, Hugel $B$, Megnien JL. Circulating microparticles may influence early carotid artery remodeling. J Hypertens. 2010;28(4):789-796. Available from: 10.1097/HJH.0b013e328335d0a8.

55. Rodrigues SF, Granger DN. Blood cells and endothelial barrier function. Tissue Barriers. 2015;3(1-2):978720-978720. Available from: $10.4161 / 21688370.2014 .978720$.

56. Bauer V, Sotnkov R. Nitric oxide - the endothelium-derived relaxing factor and its role in endothelial functions. Gen Physiol Biophys. 2010;29(4):319-359.

57. Siljander PR. Platelet-derived microparticles - An updated perspective. Thromb Res. 2011;56(2):70152-70155. Available from: $10.1016 /$ S0049-3848.

58. Stepien E, Partyka L, Janna G, Anna JG, Jarosaw G, S, et al.. Potential role of platelet derived microparticles and their aggregates in atherosclerotic plaque vascularization Frontiers in CardioVascular Biology , London 30th March - 1st April 2012 Second Congress of the ESC Council on Basic Cardiovascular Science PO; 2012. Available from: 10.1093/cvr/cvr334.

59. Walsh TG, Metharom P, Berndt MC. The functional role of platelets in the regulation of angiogenesis The functional role of platelets in the regulation of angiogenesis. Platelets. 2015;26(3):199-211. Available from: 10.3109/09537104.2014. 909022.

60. Koenen RR, Aikawa E. Extracellular Vesicle-Mediated Processes in Cardiovascular Diseases. Front Cardiovasc Med. 2018;5:133-133. Available from: 10.3389/fcvm.2018.00133.

61. Paudel KR, Panth N, Kim D. Circulating Endothelial Microparticles: A Key Hallmark of Atherosclerosis Progression. Scientifica (Cairo). 2016;2016:8514056. Available from: 10.1155/ 2016/8514056.

62. Badimon L, Padr T, Vilahur G. Atherosclerosis, platelets and thrombosis in acute ischaemic heart disease. Eur Hear J Acute Cardiovasc Care. 2012;1(1):60-74. Available from: 10.1177/ 2048872612441582.

63. Mause SF, Hundelshausen P, Von, Zernecke A, Koenen RR, Weber C. A Transcellular Delivery System for RANTES Promoting
Monocyte Recruitment on Endothelium. Arterioscler Thromb Vasc Biol. 2005;25(7). Available from: 1512-8.DOI:10.1161/01. ATV.0000170133.43608.37.

64. Strasser EF, Happ S, Weiss DR, Pfeiffer A, Zimmermann R, Eckstein $\mathrm{R}$. Microparticle detection in platelet products by three different methods. Transfusion. 2013;53(1):156-66. Available from: 10.1111/j.1537-2995.2012.03720.x.

65. Joseph EIJ, Albert T, Robert F. Clinical Relevance of Microparticles from Platelets and Megakaryocytes. Curr Opin Hematol. 2010;17:578-584. Available from: 10.1097/MOH 0b013e32833e77ee.

66. Varon D, Shai E. Platelets and their microparticles as key players in pathophysiological responses. J Thromb Haemost. 2015;13(1):40-46. Suppl. Available from: 10.1111/jth.12976.

67. Csongrdi E, Nagy B, Fulop T, Varga Z, Karnyi Z, Magyar MT. Increased levels of platelet activation markers are positively associated with carotid wall thickness and other atherosclerotic risk factors in obese patients. Thromb Haemost. 2011;106(4):683-92. Available from: 10.1160/TH11-01-0030.

68. Zhou B, Guo G, Zheng L, Zu L, Gao W. Microparticles as Nove Biomarkers and Therapeutic Targets in Coronary Heart Disease. Chin Med J (Engl). 2015;20(2):267-272. Available from: 10.4103/0366-6999.149231.

69. Ueba T, Nomura S, Inami N, Nishikawa T, Kajiwara M. Plasma Level of Platelet-Derived Microparticles Is Associated with Coronary Heart Disease Risk Score in Healthy Men. J Atheroscler Thromb. 2010;30(4):342-351. Available from: DOI:10.5551/jat.2964.

70. Koltsova EK, Sundd P, Zarpellon A, Ouyang H, Mikulski Z, Zampolli A. Genetic deletion of platelet glycoprotein lb alpha but not its extracellular domain protects from atherosclerosis. Thromb Haemost. 2014;112(6):1252-63. Available from: 10.1160/TH14-02-0130.

71. Massberg S, Brand K, Grner S, Page S, Mller I, Mller E. A Critical Role of Platelet Adhesion in the Initiation of Atherosclerotic Lesion Formation. J Exp Med. 2002;7(7):887-96. Available from: DOI:10.1084/jem.20012044.

72. Ma YQ, Qin J, Plow EF. Platelet integrin alpha (Ilb)beta(3): activation mechanisms. J Thromb Haemost. 2007;5(7). Available from: 10.1111/j.1538-7836.2007.02537.x.

73. Li X, Cong H. Platelet-Derived Microparticles and the Potential of Glycoprotein Ilb/llla Antagonists in Treating Acute Coronary Syndrome. Heart Inst J. 2009;36(2):2676586-2676586.

74. Vasina EM, Cauwenberghs S, Feijge M, Heemskerk J, Weber C, Koenen RR. Microparticles from apoptotic platelets promote resident macrophage differentiation. Cell Death Dis. 2011;2:211-211. Available from: 10.1038/cddis.2011.94.

75. Larson MK, Tormoen GW, Weaver LJ, Luepke KJ, Patel IA, Hjelmen CE. Exogenous modification of platelet membranes with the omega-3 fatty acids EPA and DHA reduces platelet procoagulant activity and thrombus formation. Am J Physiol Physiol. 2013;304(3). Available from: C273-C279.doi:10.1152/ ajpcell.00174.2012.

76. Krishnan PV, Anuradha S, Bhattacharjee J, Gaiha M. Effects of low dose omega- 3 fatty acids on platelet functions and coagulation profile in Indian patients with type 2 diabetes mellitus with vascular complications: A prospective, preliminary study. Journal, Indian Acad Clin Med. 2007;8(1):45-52.

77. Cohen MG, Rossi JS, Garbarino J, Bowling R, Motsinger-Reif $A A$, Schuler $C$. Insights into the inhibition of platelet activation by omega- 3 polyunsaturated fatty acids: Beyond aspirin and clopidogrel. Thromb Res. 2011;128(4):335-340. Available from: 10.1016/j.thromres.2011.04.023.

78. Phang M, Lincz L, Seldon M, Garg ML. Acute supplementation with eicosapentaenoic acid reduces platelet microparticle activity in healthy subjects. J Nutr Biochem. 2012;23(9):11281133. Available from: 10.1016/j.jnutbio.2011.06.006.

79. Harris S. Fatty acids and serumlipoproteins : human studies. Am J Clin Nutr. 1997;65(5):1645S-1654S. Suppl. Available from: 10.1093/ajcn/65.5.1645S. 
80. Mozaffarian D, Geelen A, Brouwer IA, Geleijnse JM, Zock $P L$, Katan MB. Effect of fish oil on heart rate in humans: A meta-analysis of randomized controlled trials. Circulation. 2005;112(13):1945-1952. Available from: 10.1161/ CIRCULATIONAHA.105.556886.

81. Geleijnse JM, Giltay EJ, Grobbee DE, Donders A, Kok FJ. Blood pressure response to fish oil supplementation: Metaregression analysis of randomized trials. J Hypertens. 2002;20(8):1493-1499. Available from: 10.1097/00004872200208000-00010.

82. Huang T, Zheng J, Chen Y, Yang B, Wahlqvist ML, Li D. High consumption of -3 polyunsaturated fatty acids decrease plasma homocysteine: A meta-analysis of randomized, placebo-controlled trials. Nutrition. 2011;27(9):863-867. Available from: 10.1016/j.nut.2010.12.011.

83. Kiecolt-Glaser JK, Belury MA, Andridge R, Malarkey WB, Hwang BS, Glaser R. Omega-3 supplementation lowers inflammation in healthy middle-aged and older adults: A randomized controlled trial. Brain Behav Immun. 2012;26(6):988995. Available from: 10.1016/j.bbi.2012.05.011.

84. Kander T, Lindblom E, Schott U. Dose-response effects of omega-3 on platelet aggregation: an observational study. J Int Med Res. 2018;p. 300060518789817-300060518789817. Available from: 10.1177/0300060518789817.

85. Rees D, Miles EA, Banerjee T, Wells SJ, Roynette CE, Wahle KW. Dose-related effects of eicosapentaenoic acid on innate immune function in healthy humans : a comparison of young. Am J Clin Nutr. 2006;83(2):331-373.

86. Effect of Dietary Enrichment with Eicosapentaenoic and Docosahexaenoic Acids on in Vitro Neutrophil and Mono- cyte Leukotriene Generation and Neutrophil Function. N Engl J Med. 1985;86:1217-1224. Available from: 10.1056/ NEJM198505093121903.

87. Aziz N, Azlan A, Ismail A, Alinafiah M, Razman S, MR. Quantitative determination of fatty acids in marine fish and shellfish from warm water of straits of malacca for nutraceutical purposes. Biomed Res Int. 2013;Available from: 10.1155/2013/ 284329.

88. Hamilton MC, Hites RA, Schwager SJ, Foran JA, Knuth BA, Carpenter DO. Lipid composition and contaminants in farmed and wild salmon. Environ Sci Technol. 2005;39(22):8622-8629. Available from: 10.1021/es050898y.

89. DG P, MY W, T CR, FH V , WC P, VA B, et al. Alterations in human leukocyte function induced by ingestion of eicosapentaenoic acid. Journal of clinical immunology. 1986;6(5):402-10. Available from: 10.1007/BF00915380.

90. Abreu SC, Lopes-Pacheco M, da ALS, Debora GX, de OTB, Jamil ZK, et al. Eicosapentaenoic acid enhances the effects of mesenchymal Stromal cell therapy in experimental allergic asthma. Front Immunol. 2015;3(5):1-12. Available from: 10.3389/fimmu.2018.01147.

91. Chang WL, Azrina A, Sabariah MN. Irmi Zarina, I Loh, SP Effects of Consuming Yellowstripe Scad versus Salmon on Lipid Profile, Fasting Glucose, Body Weight Status and Blood Pressure among Healthy Overweight Malaysian Adults. Malays Nutr;3(434-452).

92. Fish and omega-3: Questions and answers. https://www.hea rtfoundation.org.au/images/uploads/main/Programs/Consu mer_QA_Fish_Omega3_Cardiovascular_Health.pdf. 